\title{
Examination of historical paintings by state-of-the-art hyperspectral imaging methods: from scanning infra-red spectroscopy to computed X-ray laminography
}

\author{
Stijn Legrand ${ }^{1}$, Frederik Vanmeert ${ }^{1}$, Geert Van der Snickt ${ }^{1}$, Matthias Alfeld ${ }^{1,2}$, Wout De Nolf ${ }^{1}$, Joris Dik ${ }^{3}$ \\ and Koen Janssens ${ }^{1 *}$
}

\begin{abstract}
The development of advanced methods for non-destructive selective imaging of painted works of art at the macroscopic level based on radiation in the X-ray and infrared range of the electromagnetic spectrum are concisely reviewed. Such methods allow to either record depth-selective, element-selective or species-selective images of entire paintings. Camera-based 'full field' methods (that record the image data in parallel) can be discerned next to scanning methods (that build up distributions in a sequential manner by scanning a beam of radiation over the surface of an artefact). Six methods are discussed: on the one hand, macroscopic X-ray fluorescence and X-ray diffraction imaging and X-ray laminography and on the other hand macroscopic Mid and Near Infrared hyper- and full spectral imaging and Optical Coherence Tomography. These methods can be considered to be improved versions of the well-established imaging methods employed worldwide for examination of paintings, i.e., X-ray radiography and Infrared reflectography. Possibilities and limitations of these new imaging techniques are outlined.
\end{abstract}

Keywords: Painting, Non-invasive imaging, Hyperspectral imaging, Full spectral imaging, Macroscopic X-ray fluoresence, Near-infrared, Mid-Infrared, Computed X-ray Laminography, Optical Coherence Tomography

\section{Introduction}

Historical paintings are considered to be among the most precious cultural heritage artefacts and have been the subject of intensive studies for decades. Scientific studies on such artefacts are highly relevant, in order to optimize the preservation of the paintings for coming generations and/or to gain more profound insights in their creation process [1-3]. This review focusses on the examination of easel paintings, i.e., painted renditions realized on a moveable substrate. Easel painting consists typically of a support, ground, paint and varnish layers, applied on top of one another. Canvasses and wooden panels are the most popular supports, but also other materials such as thin copper plates, paper, stone and glass have been used. Often the pictorial layers are very thinly painted out, making some of them semi-transparent.

* Correspondence: koen.janssens@uantwerpen.be

'Department of Chemistry, University of Antwerp, Antwerp, Belgium Full list of author information is available at the end of the article
Micrometers below a painting's surface, a wealth of information may be present about the creative process followed by the artist while making the work of art. Many painterly effects can critically depend on the layer build-up: e.g., the translucent shine of colorful tissues, the suggestion of shadow in flesh tones or the convincing illusion of an object's texture may be realized by deliberately including the optical contribution of lower layers. Additionally, knowledge about the stratigraphy of a painting often is highly relevant in conservation when stability problems such as paint discoloration or delamination are studied. Thus, the study of a painting, its composition and stratigraphy is a common research theme shared by curators, conservators and conservation scientists. However, this information, comprised of structural and compositional aspects, is usually not easy to obtain in a non-invasive manner. Next to the visible surface layers, subsurface layers may include underdrawings, underpaintings, and adjustments made in the course of painting. 
Together, all these layers determine the current appearance of the work of art. In a growing number of cases conservators have discovered abandoned compositions underneath paintings, illustrating the artist's practice of reusing a canvas or panel. Imaging methods that can "read" this hidden information without any damage to the artwork are therefore valuable for art-historical research [2] while also being very useful during restoration activities.

The standard methods for studying the inner structure of painted works of art are X-ray radiography (XRR) and infrared reflectography (IRR), penetrative illumination techniques that are optionally complemented with the microscopic analysis of cross-sectioned samples. Both methods are full field imaging methods, employing image plates or cameras that are sensitive in the appropriate range of the electromagnetic spectrum for recording the image data (see Figure 1A). Since these methods all have their limitations, recently, a number of new approaches based on X-ray and Infra-red radiation for imaging the buildup of hidden paint layer systems have been put into practice; some of these methods make use of scanning pencil beams over the painting while recording data either in transmission or reflection mode (see Figure $1 \mathrm{~B}, \mathrm{C}$ ). Two major motivations can be discerned for the development of these more advanced versions: (a) the desire to know more about the creative process and/or the artist's way of working that have led to a given work of art and (b) the need to assess and predict the current and future condition of a work of art. Motivation (a) is essentially of art-historical nature and seeks to reconstruct (better) the past/history of an artwork while motivation (b) is more strongly linked to preventive conservation and to conservation technology, and therefore mostly concerned with the future of the artwork [1]. Of course, for conservation, an understanding of the history of a work of art and the artist's intent is fundamental, since it provides the basis for assessing the current condition of the art work and for deciding which interventions are (not) appropriate [4]. In what follows, we mainly review recent activities that involve the use of strongly penetrative radiation (from either the $\mathrm{X}$-ray or IR range of the EM spectrum); the interested reader is referred to reviews [1-4] for a broader treatment of the topic, including related spectroscopic investigations. Also Liang's 2012 review of multispectral and hyperspectral imaging using mainly visual radiation is a useful complementary resource in this respect [5].

\section{X-ray based methods}

The variants of XRR that will be discussed below in more detail are called Macroscopic X-ray fluorescence (MA$\mathrm{XRF}$ ), the related method of Macroscopic X-ray diffraction (MA-XRD) and Computed X-ray laminography (CXL). All are non-destructive techniques, eliminating the need to remove material from the artefacts for their examination. The first two allow for element- or (crystal) phaseselective imaging at the length scale of the paintings themselves while the third method is suitable for depth selective micro imaging.

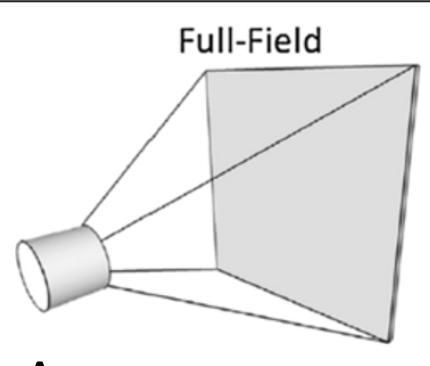

A

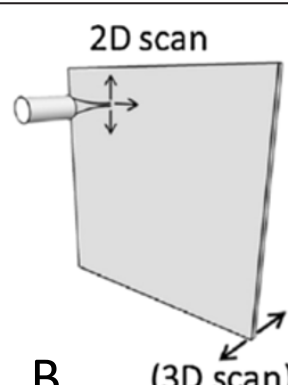

(3D scan)
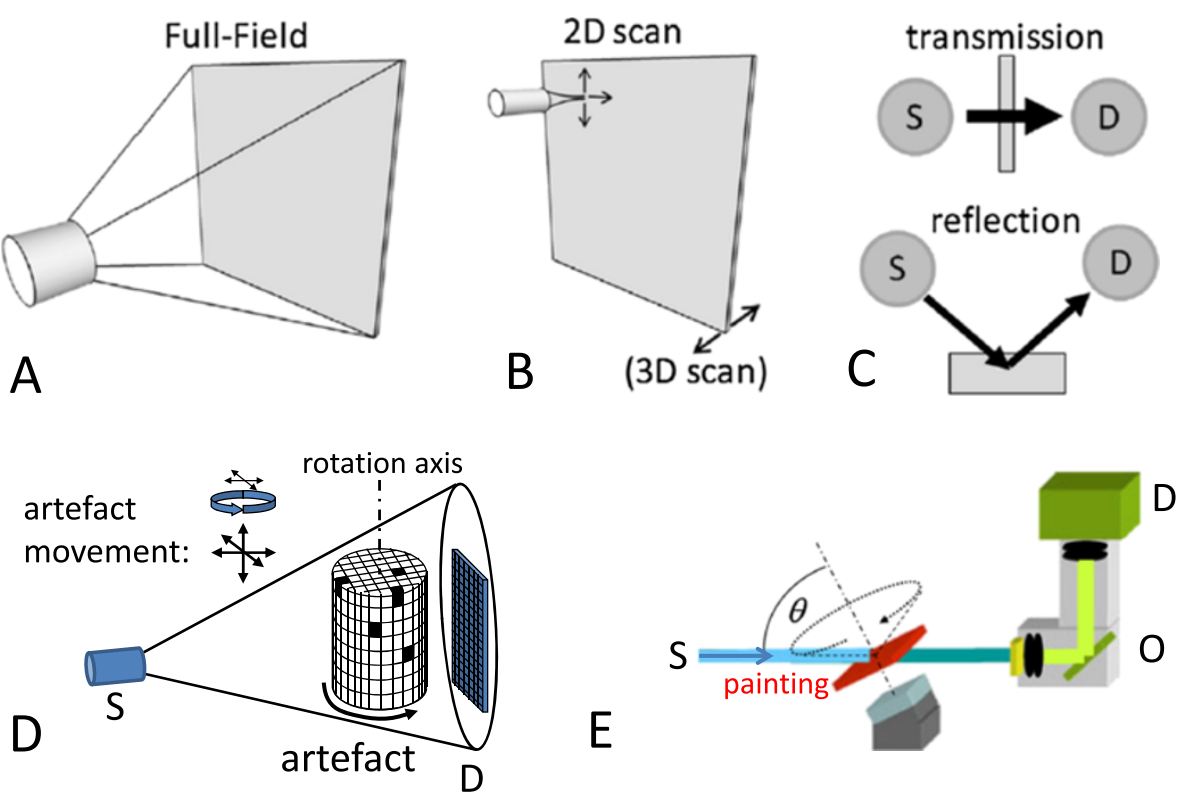

Figure 1 Schematic representation of (A) full field imaging and (B) scanning pencil-beam imaging methods: these can operate in either (C) transmission or reflection geometry; of (D) conventional computed X-ray tomography (employing cone beam illumination) and (E) computed X-ray laminography (employing parallel beam irradiation). Adapted from [4] and [2]. 


\section{Macroscopic X-ray fluorescence analysis (MA-XRF)}

XRF is a well-established method of quantitative element analysis that is based on the ionization of the atoms of the material being irradiated by an energetic beam of primary X-rays [6,7]. Characteristic radiation emitted by the ionized atoms contains information on the nature and the abundance of the elemental constituents present. The technique is particularly efficient for studying high-Z elements in low- $Z$ matrices. Since XRF meets a number of the requirements of the 'ideal method' for non-destructive analysis of cultural heritage materials [8], analysis of objects of artistic and/or archaeological value with conventional XRF is fairly common. Several textbooks cover the fundamental and methodological aspects of the method and its many variants [9]. XRF on cultural heritage and archaeological materials and artefacts is mainly used in reflection geometry. MA-XRF has recently been implemented to determine the distribution of pigments on easel paintings over large areas. Note that this method is not depth-selective so that projected pigment distributions (present at and/or below the visible paint surface) are obtained. In 2008, Dik et al. used a 38.5-keV $\mathrm{X}$-ray beam of $0.5 \mathrm{~mm}$ in diameter to record XRF spectra from a $17.5 \times 17.5 \mathrm{~cm}^{2}$ area of the painting Patch of Grass by Vincent van Gogh; this was done to visualize the portrait below the visible landscape [10]. While most of the elemental maps recorded from Patch of Grass reflect the individual paint strokes that constitute the multicolored meadow, reconstruction of the flesh tones of the hidden head of a woman was possible by combining the $\mathrm{Sb}$ (yellow-orange, Naples Yellow) and $\mathrm{Hg}$ (red, vermillion) distributions. Following this initial and promising result, the MA-XRF setup at the synchrotron facility was employed to examine paintings by Rembrandt van Rijn [11], Philipp Otto Runge [12] and several other paintings by Van Gogh [13,14]. A self-portrait by Australian artist Sir Arthur Streeton (1867-1943) that he covered at a later stage with heavy brushstrokes of lead white paint has been re-visualized by Howard et al. [15] at the Australian Synchrotron radiation facility, making use of a multiple element detector system offering very fast scanning possibilities. One of the developments permitting the use of the MA-XRF method on a larger scale has been the construction of mobile (i.e., X-ray tube based) MA-XRF scanners [14,16-18] that can be used inside the museum or picture gallery where the works of art normally are displayed or conserved. Alfeld et al. [18] has designed and optimized such a device, reporting element sensitivities that are of same order of magnitude as those of the SR-based setup employed to scan Patch of Grass. Since the SR setup employed monochromatic $38.5 \mathrm{keV}$ radiation while the mobile device employs the complete bremsstrahlung spectrum of Mo- or Rh-anode tubes bombarded with 45-50 kV electrons, the SR setup shows higher $\mathrm{K}_{\alpha}$-sensitivities for heavy elements (such as $\mathrm{Ag}, \mathrm{Cd}, \mathrm{Sn}, \mathrm{Sb}$ ) while the reverse is true for elements with atomic number below $40(\mathrm{Zr})$. The availability of the mobile MA-XRF scanner permitted the investigation of a number of paintings 'in their native environment' that normally would have been nearly impossible to transport to synchrotron facilities, either because they were too large, too fragile, too valuable or all of these. A MA-XRF scanner is commercially available from Bruker Nano GmbH (Berlin, Germany) under the name 'M6 Jetstream' [19]. Using this device, several paintings by $15^{\text {th }}, 17^{\text {th }}, 19^{\text {th }}$ and $20^{\text {th }} \mathrm{C}$. artists such as Memling, Rembrandt, Hals, Van Gogh, Magritte, Mondriaan and Pollock could be examined successfully in various museums in The Netherlands, Belgium and the USA.

As an example, Figure 2 shows results obtained by scanning the left and right panels of the Moreel tryptich, a $15^{\text {th }} \mathrm{C}$ altarpiece painted by Hans Memling. It was painted for the highly respected Moreel family of Bruges, whose members had lived in the city since the $13^{\text {th }}$ century. William Moreel, Seigneur of Oost Cleyhem, was one of the wealthiest and most politically active men in Bruges. He served as burgomaster of the city in 1478 and as treasurer in 1489. William Moreel and his second wife Barbara had eighteen children. Long before their death around 1500, they ordered the alterpiece shown in Figure 2A for their funerary chapel in the Church of St. Jacques in Bruges, founded in 1484. The lower frame of the wings and the center panel bear the same date. On the interior wings, the Moreel family is painted as kneeling devotees; the parents are represented with 16 of their children - the other two presumably were born after 1484. On the left, William Moreel is shown with his five sons behind him and flanked by his name patron saint, William of Acquitaine. On the right panel, Mrs. Moreel and her daughters kneel next to her patron saint St. Barbara. Of the eleven daughters depicted, the oldest wears the habit of a Dominican nun.

Since the X-ray radiographs of the side panels, recorded several decades ago, suggest that changes were made to the representation and position of the minor characters in both wings, MA-XRF was used to vizualise any pentimenti in the tryptich to allow for a better understanding of its evolution under the hand of Memling. Some of the MAXRF results obtained with the M6 scanner (see Figure 2B) are shown in Figure 2C-F. Usually, the MA-XRF Pb- $\mathrm{L}_{\alpha}$ distribution (Figure $2 \mathrm{C}$ ) resembles the XRR image but shows the distribution of lead white (and other lead containing pigments, if any) in a more clear fashion. When considering the copper distribution (green, Figure 2E), we notice that in the original version of the right panel, only four daughters were depicted against a landscaped background, painted with one of more $\mathrm{Cu}$-containing 


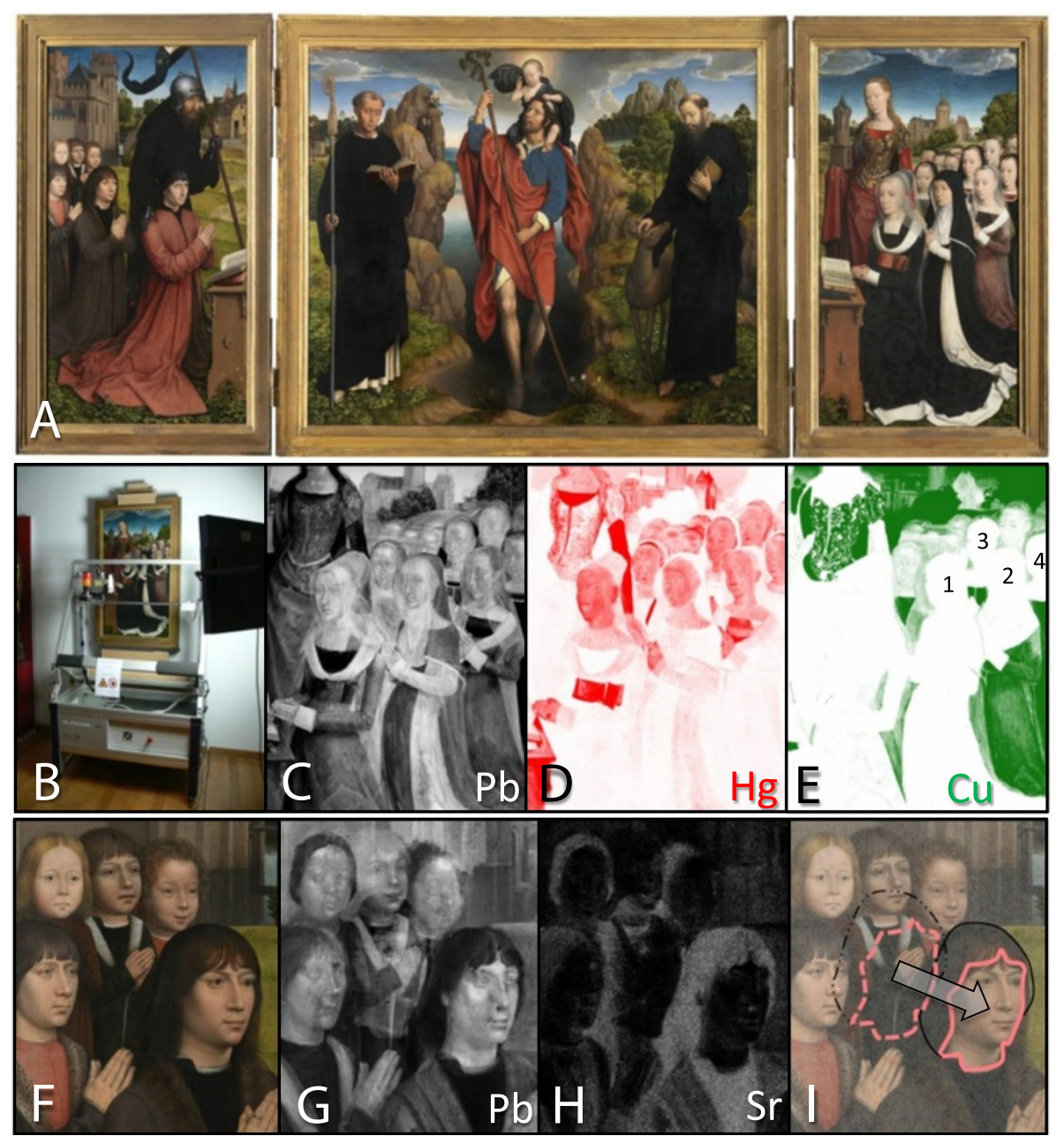

Figure 2 The Moreel Triptych, 1485, H. Memling (Groeninge Museum, Bruges, Belgium). (A) Photograph; (B) the M6 MA-XRF scanning in front of the right panel; (C-E) MA-XRF images of part of the left panel, showing Mrs. Moreel and her daughters (ca $\left.60 \times 40 \mathrm{~cm}^{2}\right)$; (F) close-up of the right panel, showing W. Moreel and his sons $\left(\mathrm{ca} 40 \times 40 \mathrm{~cm}^{2}\right)$; (G-H) corresponding MA-XRF images; (I) scheme clarifying the shift of the position of the eldest son; step size: $1 \mathrm{~mm}$ in both directions; dwell time: $0.5 \mathrm{~s} /$ pixel.

green pigments. Much more of the hill/lawn to the right of Mrs. Moreel was originally visible; in the landscape, positions were left open for her portrait and that of her (first) four daughters. The faces of the additional seven daughters were painted on top of the verdant background in a later phase. The mercury map (red, Figure 2D) shows that initially, Mrs. Moreel's hat was less elongated. Finally, in the lead distribution, it can be seen (grey/white, Figure $2 \mathrm{C}$ ) that she and her oldest daughter originally wore more revealing dresses, as is still the case for the second daughter (to the right of the nun). In left panel of the Moreel tryptich (Figure 2F) changes were made to the positions of the male children behind William Moreel: an additional portrait (of his fourth son) was inserted between that of the two boys already in the background while the eldest son was moved closer to his father (Figure 2I). The latter changes are particularly visible in the $\mathrm{Pb}$ and $\mathrm{Sr}$ images (Figure $2 \mathrm{G}$ and $\mathrm{H}$ ). From the above we can conclude that the process of creating this altar piece went through at least two major stages, a first in which the relatively young Moreel family was represented in a balanced manner against a green landscape. In order to include in a second phase all the younger children, some of the balance of the representation was sacrified by the artist. This also allowed a number of minor aspects (such as the dress of the eldest daughter) of the painting to be brought up-to-date. The above shows how the use of MA-XRF opens up the possibility for art-historians and conservators alike to explore in greater depth and with unprecedented detail the creative process that led to paintings of this type by Hans Memling and other artists. 


\section{Macroscopic XRD (MA-XRD)}

A fundamental limitation of MA-XRF stems from the fact that XRF only provides information that allows distinguishing between different chemical elements, but does not allow making the more subtle difference between, e.g. two different lead-oxide pigments such as minium $\left(\mathrm{Pb}_{3} \mathrm{O}_{4}\right)$ and litharge $(\mathrm{PbO})$. By performing macroscopic scans while signals other than X-ray fluorescence emission are recorded, this limitation may be circumvented. The first instance of XRD-based imaging of works of art was reported by Dooryhee et al. [20], making use of synchrotron radiation in reflection mode. De Nolf et al. [21] have employed very high energy radiation $(86 \mathrm{keV})$ for scanning transmission X-ray powder diffraction mapping of the distribution of pigments in mockups and original Netherlandish paintings. They concluded that highly specific identification and visualization of most pigments, even those containing the same characteristic metals (e.g., Fe in hematite and goethite) is possible, provided the angular resolution of the setup is sufficiently high. An additional advantage is that at high energy, absorption of the primary and of the diffracted beams is virtually negligible. Recently, this MA-XRD capability was successfully transferred to the laboratory by making use of a combination of a compact mirror-focussed X-ray source $(\mathrm{Ag}-\mathrm{I} \mu \mathrm{S}$, Incoatec $\mathrm{GmbH}$, Hamburg, D), emitting monochromatic Ag- $\mathrm{K}_{\alpha}$ radiation of $22 \mathrm{keV}$ and a single photon counting diffraction camera (Pilatus $200 \mathrm{~K}$, Dectris GmbH, Switzerland) [Vanmeert F, Janssens K, De Nolf W, Legrand S, Van der Snickt G, Dik J: Scanning Macroscopic X-ray powder diffraction imaging (MA-XRPD): transfer from the synchrotron to the laboratory, submitted] (see Figure 3A). As an example of the imaging possibilities of this newly constructed device, Figure $3 \mathrm{~B}$ shows the distribution of the $\mathrm{Pb}$ containing pigments hydrocerussite $\left[2 \mathrm{PbCO}_{3} \cdot \mathrm{Pb}(\mathrm{OH})_{2}\right]$ and Naples' yellow $\left[\mathrm{Pb}_{2} \mathrm{Sb}_{2} \mathrm{O}_{7}\right]$ in a copy of a baroque painting entitled The Education of Mary (original painted 1630-1635 by P.P. Rubens). The images have a spatial resolution of $0.5 \mathrm{~mm}$. Both the MA-XRF $\mathrm{Hg}$ distribution and the MA-XRD Cinnabar $(\alpha-\mathrm{HgS})$ image show that this red pigment was only used very sparingly to paint Mary's lips and to create a faint blush on her cheeks. The use of lead antimonate (found in nature as the mineral bindheimite) to render the halo around Mary's head is consistent with a mid- $18^{\text {th }}$ to late- $19^{\text {th }}$ century date of origin of this smaller copy of the original Rubens painting. The higher specificity of XRD allows readily distinguishing and identifying the pigments in a direct and positive manner while this is only possible in an indirect manner on the basis of the corresponding MA-XRF images (Figure $3 \mathrm{C}$ ). The higher energy of the diffracted $\mathrm{X}$ rays as opposed to that of the characteristic XRF radiation also allows to probe deeper for representations that may be hidden below the surface.

\section{Computed X-ray Laminography (CXL)}

A limitation shared by MA-XRF, MA-XRD and XRR is the fact that they provide projection images, i.e., they do not reveal information on the distribution of (one or more) pigments in a single layer but rather in a series of superimposed paint layers. To separate out the contributions from the different paint layers, a tomographic data collection approach $[22,23]$ or, in the case of (MA-)XRF, a confocal detection geometry [24,25] may be employed. Computed X-ray tomography (CXT) involves the recording of a series of two-dimensional radiographies under many different orientations of the sample relative to the $\mathrm{X}$-ray source-detector axis; the principle is illustrated in Figure 1D for the case of cone-beam illumination [26]. For CXT, the shape of artefacts being examined should be such that under all observation/irradiation angles, the total

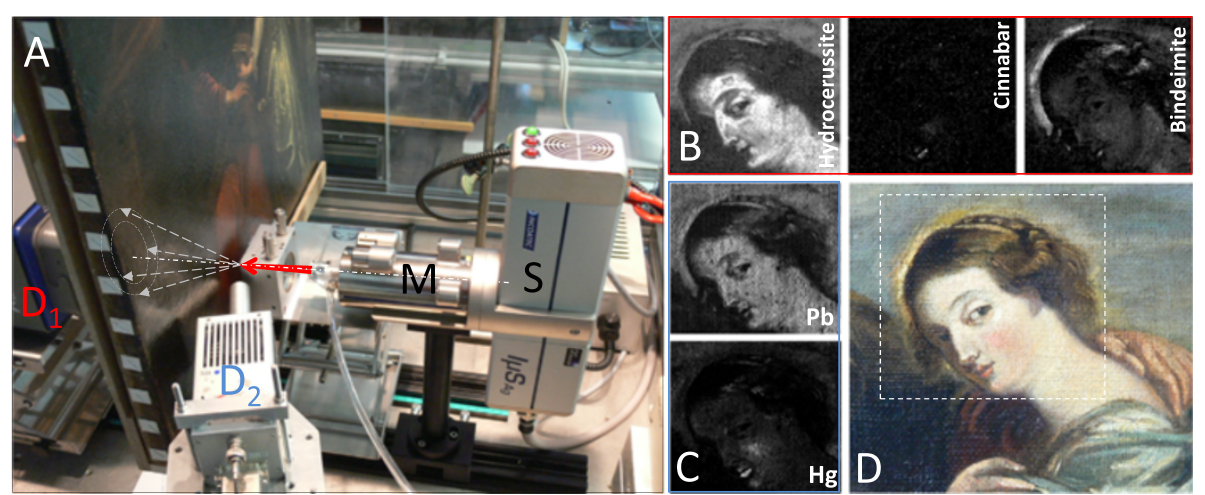

Figure 3 Prototype MA-XRD setup at the University of Antwerp. A) Photograph showing the micro-focus X-ray tube source (S), equipped with a double curved mirror $M$ and detector for recording transmission XRD $\left(D_{1}\right)$ and XRF $\left(D_{2}\right)$ data: these components are positioned close to a painting mounted on a motorized stage; B) MA-XRD and C) MA-XRF images obtained by scanning a detail of the painting shown in D): scan size: $78 \times 75$ mm², image step size: $0.5 \mathrm{~mm}$ in both directions, Dwell time: 2 s/pixel. Adapted from (Vanmeert F, Janssens K, De Nolf W, Legrand S, Van der Snickt G, Dik J: Scanning Macroscopic X-ray powder diffraction imaging (MA-XRPD): transfer from the synchrotron to the laboratory, submitted]. 
path length the transmitted radiation must follow through the absorbing material does not vary more than, say, an order of magnitude. In case of paintings and other objects that are much more extended along two dimensions (length, width) than along the third (depth), conventional CXT therefore cannot be employed; during the rotating motion of the painting relative to the source-detector axis, in a particular orientation, its entire length or width would be in the radiation path, blocking all transmission. A way of circumventing this problem is to employ the related method of computed X-ray laminography (CXL), originally developed for inspection of complex, flat, multilayered objects such as printed circuit boards [27-29]. CXL makes use of a rotation around an axis that is not perpendicular to the radiation source/detector axis but that is tilted relative to it (Figure 1E). By performing experiments on mock-up paintings, Krug et al. [30] demonstrated that voids and hidden compartments inside paintings can be inspected in a non-destructive manner via this technique.
Figure 4 illustrates how CXL allows high-resolution imaging of the local sub-surface microstructure in paintings in a non-invasive and non-destructive way. Results of feasibility tests on a painting mockup (consisting of an oak panel, a chalk ground superimposed with vermilion and lead white paint layers, see Figure $4 \mathrm{AB}$ ) show that achieving lateral and depth resolutions of up to a few micrometres is possible. Based on absorption and phase contrast, the method can provide high-resolution 3D maps of the paint stratigraphy (Figure 4C), including the wooden substrate, and visualize small features, such as pigment particles, voids, cracks, cells in the wood support etc. (Figure 4D). In resulting virtual cross sections (Figure 4EF) the local density and chemical composition of the different paint layers are visible due to increased attenuation of X-rays by elements of higher atomic number. A typical CXL scan consists of 1000 to 3600 radiographs, each with a size of 2048 by 2048 pixels and a pixel size of 0.28 to 1.4 micrometers. While each
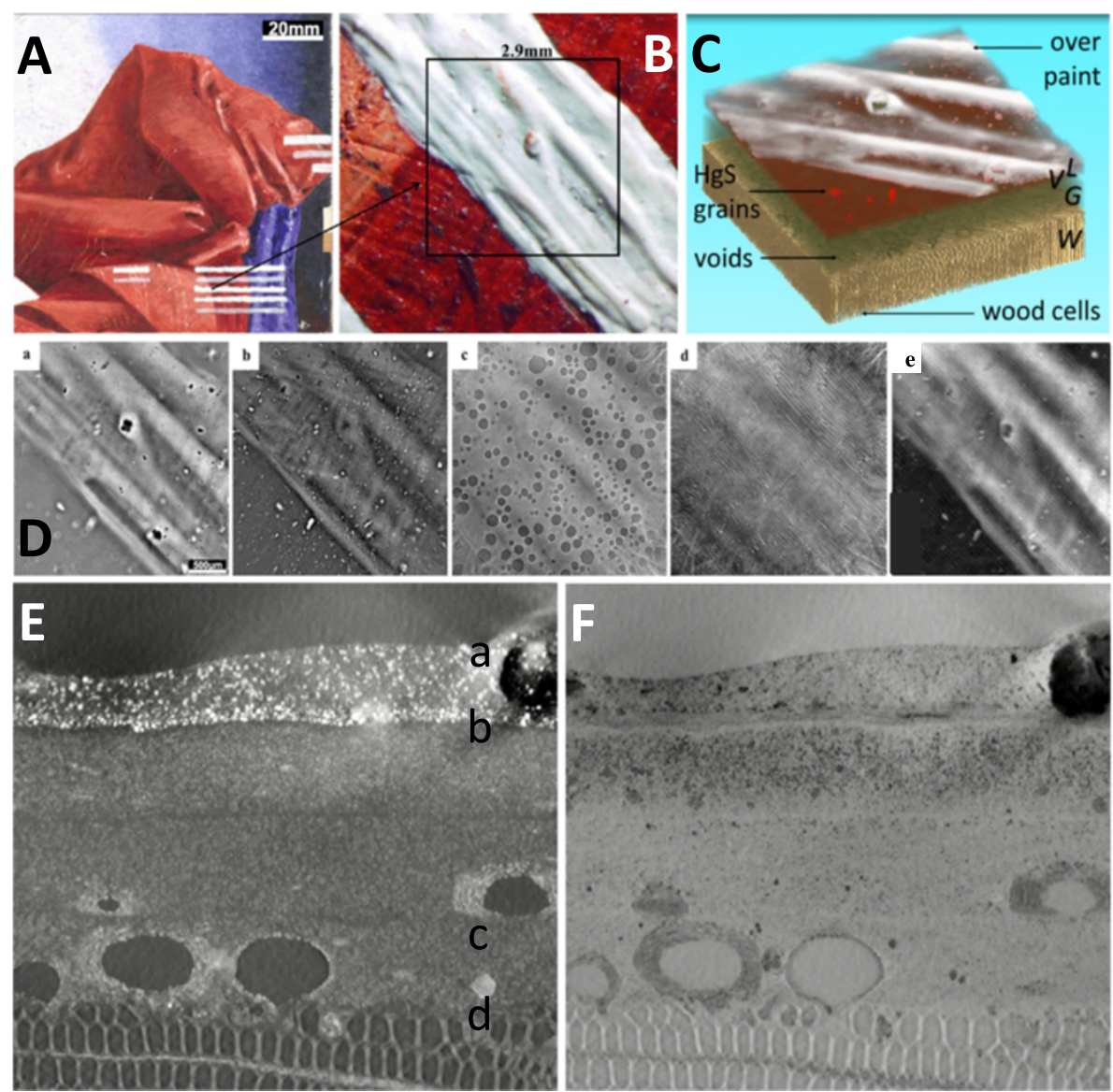

Figure 4 Mockup painting used for evaluating CXL. A: Visual photograph; B: detail of A, showing a stroke of lead white covering the red surface of the painting; $\mathbf{C}: 3 D$ rendering of $C X L$ data, showing the reconstructed volume; $\mathbf{D}$ : series of virtual laminographic sections a-d, parallel to the wood/paint surface at the depth indicated in E: (a) superficial lead white, (b) pigment particles in the red paint; (c) spherical voids in the ground layer; (d) cells in the wood support; panel (e) shows the corresponding radiography of the volume shown in $\mathbf{C} ; \mathbf{E}$, $\mathbf{F}$ : virtual cross sections obtained by applying a maximum (E) or a minimum (F) filter of 750 images, oriented perpendicular to the axis of the wood cells. Adapted from [32]. 
image is only exposed for $0.1 \mathrm{~s}$, the speed with which the painting can be rotated is limited; thus, per data set of the order of $1 \mathrm{~h}$ of total collection time was required.

Thus, this method is well adapted to study the temporal evolution of the stratigraphy in test specimens and offers an alternative to destructive sampling of original works of art. In a fashion very similar to that used with high magnification optical microscopes, the laminographic technique allows to obtain detailed morphological images at any depth in an (optically opaque) paint layer stack [31,32]. CXL thus presents a non-invasive and non-destructive alternative to sampling and polishing where such fine structure needs to be preserved. The technique has a high potential in studying conservation problems on test specimens or original works of art, where the microstructure of carrier, ground or paint is of importance but sample removal is to be avoided.

\section{Methods based on infrared radiation}

IRR was introduced in the 1960's by J.R.J. van Asperen de Boer, using PbS-based Vidicon tubes as recording devices and has seen important technological improvements over the past years [33-35]. An infra-red (IR) source of around $1.2 \mu \mathrm{m}$ is used to illuminate objects; this radiation will readily penetrate through a number of commonly occurring paint constituents such as lead white, while becoming strongly absorbed by others such as carbon black. The radiation $(0.9-1.7 \mu \mathrm{m})$ reflected by the illuminated objects is now typically recorded with a InGaAs (or equivalent) camera, allowing for rapid acquisition of high definition images with a resolution up to $0.1 \mathrm{~mm}$, covering areas of typically $0.5 \times 0.5 \mathrm{~m}^{2}$. Over the past decades, IRR has become a routine form of analysis in many painting collections, almost exclusively for the study of carbon-based underdrawings in paintings from the 16th century and earlier. In such artefacts, IR-absorbing carbon black tracery is often applied on IR-reflective chalk or gypsum grounds, resulting in a strong contrast in the reflectograms. Examination of $17^{\text {th }}$ or $18^{\text {th }}$ century paintings with IRR tends to be less rewarding because these later paintings often were set up in sketchy touches of earth pigments, or underdrawn in white chalk. These pigments are very poor infrared absorbers. Furthermore, many $17^{\text {th }}$ century paintings were painted on colored grounds that poorly reflect IR. Another limiting factor is that many of the paints contain infrared absorbing pigments, such as carbon black, that make it hard to distinguish the underlying drawings from the covering paint layers. Next to the acquisition of full field reflection images by IR-sensitive cameras, scanning may also be employed. Already in 2006, Saunders et al. [35] devised a camera system that acquired 25 Mpixel IRRs with a lateral resolution of $100 \mu \mathrm{m}$; it incorporated a small $(320 \times 256$ pixel $)$ moving InGaAs sensor of which the images were stitched together. This lightweight camera, suitable for in-situ measurements, is commercially available (OSIRIS camera) and is sensitive in the 0.9-1.7 $\mu \mathrm{m}$ wavelength range. The camera itself does not offer any means of wavelength dispersion or selection, but via absorption filters the spectral range effectively acquired can be adjusted to optimize the vizualisation of underdrawing material. Daffara et al. have described an advanced scanner that records 14 bands from 0.7 to $2.3 \mu \mathrm{m}$ and that allows for multispectral imaging of large paintings, achieving a spatial resolution of $0.5 \mathrm{~mm}$ [36]. Fast movement of the scanner head in front of the painting allows recording IRR maps of $1 \mathrm{~m}^{2}$ areas within a period of several hours at maximum resolution.

Delaney et al. have more recently described a novel near-infrared (NIR) system that allows for hyperspectral imaging in 342 narrow wavelength bands situated in the $1.0-2.5 \mu \mathrm{m}\left(4000-10000 \mathrm{~cm}^{-1}\right)$ range [37-41]. The system incorporates a scan mirror, an imaging lens, a transmission grating spectrometer + relay lens and a cryo-cooled $(640 \times 512$ pixel $) \mathrm{InSb}$ sensor. The area examined is scanned one-dimensionally by rotation of the mirror while the other camera dimension is used for wavelength dispersion. In a number of cases where the results of MA-XRF do not significantly differ from those obtained by XRR, for example in the case where very thick overpainted layers of lead white are present, this system has allowed to obtain contrast-rich imaging information. This complementarity was recently underscored during the examination of a painting by R. Magritte, called Le Portrait (1934, Museum of Modern Art, New York City, USA) by means of a combination of traditional XRR, MAXRF and NIR-hyperspectral imaging [Van der Snickt G, Martins A, Duffy M, McGlinchey C, Coddington J, Delaney JK, Janssens K, Dik J: Multimodal examination of 'Le portrait' by R. Magritte by means of X-ray and Infrared hyperspectral imaging methods reveals an overpainted representation, submitted]. The combined use of the resulting images allowed art historians of MoMA to identify the work present below the surface as La Pose Enchantée, a painting erroneously believed lost that was made by Magritte in 1927 but overpainted in 1935.

Also in the mid infrared (MIR) range, a tendency towards hyperspectral imaging and even full spectrum recording at all pixel positions is discernable. Promising results have been recently reported by Rosi et al. [42] using a novel hyperspectral imaging system (Hi90, Bruker Optics), originally developed for the remote identification and mapping of hazardous compounds. It is based on a focal-plane array mercury cadmium telluride (FPA-MCT) detector having $256 \times 256$ pixels. This device operates in the $900-1300 \mathrm{~cm}^{-1}(7.7-11.0 \mu \mathrm{m})$ spectral range and allows for the parallel recording of series of MIR spectra 
(with adequate spectral resolution $-4 \mathrm{~cm}^{-1}$ ), corresponding to each pixel of the investigated area. It was successfully used for mapping of both organic and inorganic compounds in a painting by A. Burri. Daffara et al. also have reported on a device operating in the $2000-3000 \mathrm{~cm}^{-1}$ (3.3-5.0 $\mu \mathrm{m})$ range [43].

In view of these promising results, and in analogy of the MA-XRF and MA-XRD scanners discussed above, Legrand et al. $[44,45]$ have recently explored the possibilities and limitations of a prototype macroscopic MIR-FTIR scanner, based on the Alpha Bruker FTIR spectrometer. The latter is a compact, light-weight FTIR spectrometer operating in the $400-7500 \mathrm{~cm}^{-1}$ (1.3-25.0 $\mu \mathrm{m})$ range, incorporating a globar IR-source and a deuterated triglycine sulphate (DTGS) detector that can be fitted with a reflection mode accessory. The curved mirrors in the latter produce a roughly circular IR beam of ca $2 \times 2 \mathrm{~mm}^{2}$ with which a single spot on a painting may be interrogated. During the scanning operation, the entire spectrometer is moved in an XY fashion in front of the painting while series of FTIR spectra are recorded in reflection mode from many points. Figure 5 compares results obtained by MA-rFTIR and MA-XRF from a small $(8 \times 8 \mathrm{~cm}) 20^{\text {th }}$ century, unvarnished folk-art panel painting of Antillean origin. It is built up of a number of strongly contrasting coloured areas and has a fairly simple stratigraphy, in most cases consisting of only one paint layer applied on a calcite ground. MA-XRF analysis of this painting (see Figure 5, lower row) reveals the presence of the elements cadmium, selenium and barium in the red and orange regions, strongly suggesting that the pigment employed here is cadmium lithopone $(\mathrm{CdSe}+$ $\left.\mathrm{BaSO}_{4}\right)$. Cadmium-based pigments have, due to the heavy atomic mass of cadmium, their fundamental bands in the far-IR (FIR) region and therefore cannot be detected with the MIR setup. The map in Figure 5B (1173-1260 $\left.\mathrm{cm}^{-1}\right)$ however, shows that the distribution of the sulphate ion via its symmetric stretching vibration mode $\left(v_{3}-\mathrm{SO}_{4}{ }^{2-}\right)$ is strongly correlated to the Cd MA-XRF maps of Figure 5F, corroborating the hypothesis about the presence of cadmium lithopone in the orange areas. The MA-XRF-data also show that the main yellow pigment present in this painting contains the elements lead and chromium; in the FTIR spectra, it is identified by its chromate- $\left(v_{4}\right.$ $\mathrm{CrO}_{4}{ }^{2-}$ at $\left.888 \mathrm{~cm}^{-1}\right)$ and sulphate- $\left(v_{4}-\mathrm{SO}_{4}{ }^{2-}\right.$ at 604 and $630 \mathrm{~cm}^{-1}$ ) ion bands as chrome yellow (in its pale $\mathrm{PbCr}_{1-\mathrm{x}} \mathrm{S}_{\mathrm{x}} \mathrm{O}_{4}$ form), a pigment that is in use since the $19^{\text {th }}$ century [46]. Accordingly, the map in Figure 5C, based on the $\mathrm{CrO}_{4}{ }^{2-}$ asymmetric stretch (890-950 $\mathrm{cm}^{-1}$ ) shows a good correlation with the chromium XRF image (Figure 5G). By means of the rFTIR maps, it was also possible to identify the blue and green pigments present in this painting in an unambiguous manner as phthalocyanine-based compounds. Since this group of pigments was only discovered in the 1930s, their presence confirms the presumed $20^{\text {th }}$ century origin of the painting. The metal-ligand band at $898 \mathrm{~cm}^{-1}$ suggest that copper is the metal ion in the complex, a hypothesis that is confirmed by the MA-XRF copper map of Figure $5 \mathrm{H}$. The phthalocyanine-blue (PB15) distribution (Figure 5D) can be visualized by means of its $\mathrm{C}-\mathrm{H}$ out-of-plane bending mode at $729-740 \mathrm{~cm}^{-1}$. Phthalocyanine green (PG7) is a partially chlorinated version of PB15 and this substitution results in a shift of the $\mathrm{C}$ - $\mathrm{H}$ out-of-plane bending mode band of this pigment towards higher wavenumbers, in this case to $747-762 \mathrm{~cm}^{-1}$ (Figure 5E). For confirmation, the copper and chlorine XRF-maps are also shown in Figure 5H and I. While the MA-XRF copper map resembles the sum distribution of both pigments, the chlorine distribution of Figure 5I only resembles the FTIR map of PG7. It is possible to conclude from the above that the species-specific MA-rFTIR maps allow visualization of the distribution of these highly similar pigments in a straightforward and reliable manner, even

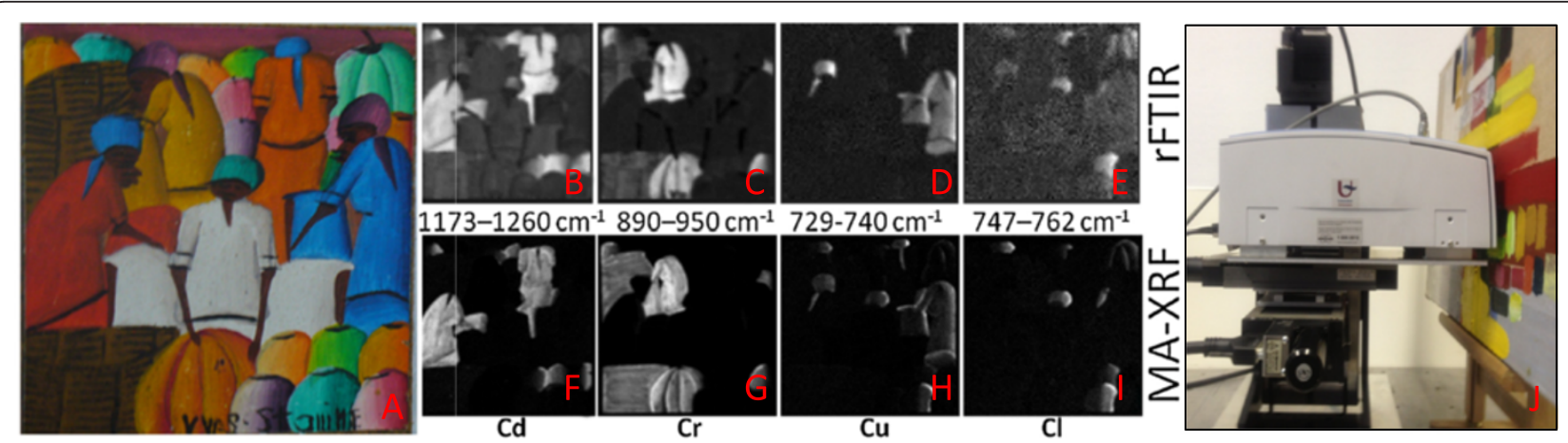

Figure 5 Antillean folk art painting $\left(8 \times 8 \mathbf{c m}^{2}\right)$, of assumed $20^{\text {th }}$ Century origin. A) Visual image; MA-rFTIR chemical distribution images: B) cadmium lithopone $\left(1173-1260 \mathrm{~cm}^{-1}\right)$, C) chrome yellow $\left(890-950 \mathrm{~cm}^{-1}\right)$, D) phthalocyanine blue $\left(729-740 \mathrm{~cm}^{-1}\right)$ and E) phthalocyanine green (747-762 $\mathrm{cm}^{-1}$ ); MA-XRF elemental distribution maps of F) cadmium, G) chromium, $\mathbf{H}$ ) copper and I) chlorine: lighter tones indicate higher levels of net pseudo absorbance or X-ray fluorescence intensity; J) Photograph of MA-rFTIR device in front of a large canvas, scanned area: $76 \times 76 \mathrm{~mm}^{2}$, step size: $1 \mathrm{~mm}$ in both directions, dwell time: 8 s/pixel. Adapted from [44]. 
though in its current implementation, very long acquisition times are required for this. Considering these results, that illustrate the advantages of recording full spectral data at all positions of an examined painting area may entail, it is expected that hyper- and full spectral imaging of paint surfaces in the IR fingerprint region will open up new and broad perspectives for non-invasive analysis.

It must be mentioned here that the mid-FTIR based methods are severely hampered by the presence of varnish (or other organic cover) layers and in practice can only be employed on paintings that are not varnished or those where the varnish has been temporarily removed. This important limitation is not present with the X-ray based imaging methods discussed above where both primary and secondary (XRF) radiation can easily penetrate any cover layers.

A related and notable development of recent years is the depth selective variant of NIR-based imaging called Optical Coherence Tomography (OCT) $[47,48]$. OCT is a point scanning system based on the use of a NIR source coupled to a Michelson interferometer. The source, similar to those used for conventional IRR, illuminates both a reference mirror and the object under examination. Constructive interference occurs when the length of the optical path of the light that is backscattered within the object matches, within the coherence length, the length of the optical path of the radiation reflected by the mirror. The interference measurement therefore enables the determination of the depth at which the reflection took place within the object. This adds depth-resolution to the infra-red investigation of paintings, allowing mapping of the distribution of specific materials and material interfaces throughout the paint stratigraphy. The technique proves to be a powerful imaging tool in the study of thinly painted layers as found in 16th century and earlier paintings $[49,50]$. The technique is particularly valuable for the study of near-surface features, notably translucent layers such as glazes and varnish [51].

\section{Conclusions}

In this paper a brief overview was presented of recent methodological and instrumental developments regarding the characterization of painted works of art based on either penetrative X-ray or Infrared radiation. Macroscopic XRF is a variant of the general method of X-ray fluorescence analysis that is well suited to visualize the elemental distribution of key elements, mostly metals, present in areas of around $0.5-1 \mathrm{~m}^{2}$ or more. This method is not depth-selective so that projected pigment distributions (at and/or below the visible paint surface) are obtained. For depth-selective imaging of the individual layers in a painting, on the other hand X-ray laminography, a variant of computed X-ray tomography that is more suitable for examination of flat panels, appears promising.
Also by means of OCT, depth resolved imaging appears possible, albeit in materials that retain a certain transparency. By means of infrared radiation, either in the NIR or in the MIR ranges, camera-based or scanning based reflection mode imaging can be performed. The information obtained in this manner is often complementary to that obtained by means of the X-ray based methods. The combined use of MA-XRF/XRD scanning with NIR/MIR hyperspectral imaging or MA-rFTIR scanning appears to be a very promising new direction for non-invasive imaging of paintings.

\section{Competing interests}

The authors declare that they have no competing interests.

\section{Authors' contributions}

$\mathrm{SL}$ and $\mathrm{KJ}$ wrote the manuscript which was revised by FVM, GvdS, MA and JD. SL, MA, GvdS and FVM constructed equipment and performed analytical measurements. MA and WDN wrote data processing and reduction software. All authors read and approved the final manuscript.

\section{Acknowledgements}

The authors acknowledge support from the Hercules fund, Brussels (grant A11/0387), BELSPO (Brussels) through project S2-ART (SD04A) and FWO (Brussels) via grant G.OC12.13. Support was also received from NWO (Den Haag) via the Science4Art programme. Additionally the University of Antwerp Research council in acknowledged for granting a PhD scholarship to S.L. The authors are indebted to the staff of the Groeninge museum for their assistance with the MAXRF measurements.

\section{Author details}

${ }^{1}$ Department of Chemistry, University of Antwerp, Antwerp, Belgium. ${ }^{2}$ Photon Science, Deutsches Elektronen Synchrotron (DESY), Hamburg, Germany. ${ }^{3}$ Department of Materials Science, Delft University of Technology, Delft, The Netherlands.

Received: 17 February 2014 Accepted: 7 May 2014

Published: 30 May 2014

\section{References}

1. Cotte M, Susini J, Dik J, Janssens K: Synchrotron-Based X-ray Absorption Spectroscopy for Art Conservation: Looking Back and Looking Forward. Acc Chem Res 2010, 43:705-714.

2. Janssens K, Dik J, Cotte M, Susini J: Photon-based techniques for nondestructive subsurface analysis of painted cultural heritage artifacts. Acc Chem Res 2010, 43:814-825.

3. Janssens K, Alfeld M, Van der Snickt G, De Nolf W, Vanmeert F, Radepont M, Monico L, Dik J, Cotte M, Falkenberg G, Miliani C, Brunetti BG: The use of synchrotron radiation for the characterization of artists' pigments and paintings. Annu Rev Anal Chem 2013, 6:399-425.

4. Alfeld M, Broekaert JAC: Mobile depth profiling and sub-surface imaging techniques for historical paintings - A review. Spectrochim Acta B At Spectrosc 2013, 88:211-230.

5. Liang $\mathrm{H}$ : Advances in multispectral and hyperspectral imaging for archaeology and art conservation. Appl Phys A Mater Sci Process 2012, 106:309-323.

6. Janssens K, Adams F, Rindby A: Microscopic X-ray fluorescence analysis. Chichester, UK: John Wiley \& Sons; 2000.

7. Beckhoff B, Kanngiesser B, Langhoff N, Rainer W, Helmut W: Handbook of Practical X-Ray Fluorescence Analysis. Berlin, Heidelberg, Germany: Springer Verlag; 2006.

8. Lahanier C, Amsel G, Heitz C, Menu M, Andersen HH: Proceedings of the International Workshop on lon-Beam Analysis in the Arts and Archaeology - Pont-A-Mousson, Abbaye des Premontres, France, February 18-20, 1985 - Editorial. Nucl Instrum Methods Phys Res B Beam Interact Mater Atoms 1986, 14:R7-R8.

9. Van Grieken R, Markowicz A: Handbook of X-ray Spectrometry. New York, USA: Marcel Dekker; 2002. 
10. Dik J, Janssens K, Van der Snickt G, van der Loeff L, Rickers K, Cotte M: Visualization of a lost painting by Vincent van Gogh using synchrotron radiation based X-ray fluorescence elemental mapping. Anal Chem 2008 80:6436-6442.

11. Dik J, Alfeld M, Janssens $K$, van de Wetering E: Nouveau type d'examen aux rayons $x$ d'un Rembrandt dissimule. In Un Nouveau regard sur Rembrandt. Edited by van de Wetering E. Amsterdam, The Netherlands: Local World; 2009.

12. Alfeld M, Janssens K, Appel K, Thijsse B, Blaas J, Dik J: A portrait by Philipp Otto Runge - visualizing modifications to the painting using synchrotron-based X-ray fluorescence elemental scanning. Zeitschrift für Kunsttechnologie und Konservierung 2011, 25:157-163.

13. Struick van der Loeff $L$, Alfeld M, Meedendorp T, Dik J, Hendriks E, van der Snickt G, Janssens K, Chavannes M: Rehabilitation of a flower still life in the Kröller-Müller Museum and a lost Antwerp painting by Van Gogh. In Van Gogh: New Findings. Edited by van Tilborgh L. Amsterdam, The Netherlands: Van Gogh Museum; 2012.

14. Alfeld M, Van der Snickt G, Vanmeert F, Janssens K, Dik J, Appel K, van der Loeff L, Chavannes M, Meedendorp T, Hendriks E: Scanning XRF investigation of a Flower Still Life and its underlying composition from the collection of the Kroller-Muller Museum. Appl Phys A Mater Sci Process 2013, 111:165-175.

15. Howard DL, de Jonge MD, Lau D, Hay D, Varcoe-Cocks M, Ryan CG, Kirkham R, Moorhead G, Paterson D, Thurrowgood D: High-definition x-ray fluorescence elemental mapping of paintings. Anal Chem 2012, 84:3278-3286.

16. Hocquet FP, del Castillo HC, Xicotencatl AC, Bourgeois C, Oger C, Marchal A, Clar M, Rakkaa S, Micha E, Strivay D: Elemental 2D imaging of paintings with a mobile EDXRF system. Anal Bioanal Chem 2011, 399:3109-3116.

17. Bull D, Krekeler A, Alfeld M, Dik J, Janssens K: An intrusive portrait by Goya. Burlingt Mag 2011, 153:668-673.

18. Alfeld M, Janssens K, Dik J, de Nolf W, van der Snickt G: Optimization of mobile scanning macro-XRF systems for the in situ investigation of historical paintings. J Anal At Spectrom 2011, 26:899-909.

19. Alfeld M, Pedroso JV, Hommes MV, Van der Snickt G, Tauber G, Blaas J, Haschke M, Erler K, Dik J, Janssens K: A mobile instrument for in situ scanning macro-XRF investigation of historical paintings. J Anal At Spectrom 2013, 28:760-767.

20. Dooryhee E, Anne M, Bardies I, Hodeau JL, Martinetto P, Rondot S, Salomon J, Vaughan GBM, Walter P: Non-destructive synchrotron X-ray diffraction mapping of a Roman painting. Appl Phys A Mater Sci Process 2005, 81:663-667.

21. De Nolf W, Dik J, Vandersnickt G, Wallert A, Janssens K: High energy X-ray powder diffraction for the imaging of (hidden) paintings. J Anal At Spectrom 2011, 26:910-916.

22. Ferreira ESB, Boon JJ, van der Horst J, Scherrer NC, Marone F, Stampanoni M: 3D Synchrotron X-Ray Microtomography of Paint Samples. In O3a: Optics for Arts, Architecture, and Archaeology, Proceedings SPIE 7391. Edited by Pezzati L, Salimbeni R. Bellingham, WA, USA: Int. Soc. for Optical Engineering; 2009

23. De Nolf W, Janssens K: Micro X-ray diffraction and fluorescence tomography for the study of multilayered automotive paints. Surf Interface Anal 2010, 42:411-418.

24. Mass $J$, Woll A, Bisulca C: Confocal X-ray fluorescence of paintings: Imaging a missing NC Wyeth. Abstr Pap Am Chem Soc 2009, 238:1.

25. Mass J, Bisulca C: Revealed, a Lost Illustration by N.C. Wyeth. In Antiques and Fine Art. Summer/Autumn 2010 ed. Watertown, MA, USA: Pure Imaging Inc; 2010.

26. Zhang X, Blaas J, Botha C, Reischig P, Bravin A, Dik J: Process for the 3D virtual reconstruction of a microcultural heritage artifact obtained by synchrotron radiation $\mathrm{CT}$ technology using open source and free software. J Cult Herit 2012, 13:221-225.

27. Helfen L, Baumbach T, Cloetens P, Baruchel J: Phase-contrast and holographic computed laminography. Appl Phys Lett 2009, 94:104103.

28. Helfen L, Baumbach T, Mikulik P, Kiel D, Pernot P, Cloetens P, Baruchel J: High-resolution three-dimensional imaging of flat objects by synchrotron-radiation computed laminography. Appl Phys Lett 2005, 86:071915

29. Helfen L, Xu F, Suhonen H, Cloetens P, Baumbach T: Laminographic Imaging Using Synchrotron Radiation - Challenges and Opportunities. In Proceedings 11 th International Conference on Synchrotron Radiation Instrumentation. Edited by Susini J, Dumas P. 2013.
30. Krug K, Porra L, Coan P, Wallert A, Dik J, Coerdt A, Bravin A, Elyyan M, Reischig P, Helfen L, Baumbach T: Relics in medieval altarpieces? Combining X-ray tomographic, laminographic and phase-contrast imaging to visualize thin organic objects in paintings. J Synchrotron Radiat 2008, 15:55-61.

31. Dik J, Reischig P, Krug K, Wallert A, Coerdt A, Helfen L, Baumbach T: Threedimensional imaging of paint layers and paint substructures with synchrotron radiation computed mu-laminography. J Am Inst Conserv 2009, 48:185-197.

32. Reischig P, Helfen L, Wallert A, Baumbach T, Dik J: High-resolution non-invasive 3D imaging of paint microstructure by synchrotron-based X-ray laminography. Appl Phys A Mater Sci Process 2013, 111:983-995.

33. Van Asperen de Boer J: Scientific Examination of Early Netherlandish Painting. In An Introduction to the Scientific Examination of Paintings. Edited by Filedt Koj JP. Bussum,The Netherlands: Fibula - van Dishoeck; 1976:1-40.

34. Liang $H$, Saunders D, Cupitt J: A new multispectral imaging system for examining paintings. J Imaging Sci Technol 2005, 49:551-562.

35. Saunders D, Billinge R, Cupitt J, Atkinson N, Liang H: A new camera for high-resolution infrared imaging of works of art. Stud Conserv 2006, 51:277-290

36. Daffara C, Pampaloni E, Pezzati L, Barucci M, Fontana R: Scanning multispectral IR reflectography SMIRR: an advanced tool for art diagnostics. Acc Chem Res 2010, 43:847-856.

37. Delaney JK, Zeibel JG, Thoury M, Littleton R, Palmer M, Morales KM, de la Rie ER, Hoenigswald A: Visible and Infrared imaging spectroscopy of Picasso's Harlequin musician: mapping and identification of artist materials in Situ. App/ Spectrosc 2010, 64:584-594

38. Thoury M, Delaney JK, Rene de la Rie E, Palmer M, Morales K, Krueger J: Near-infrared luminescence of cadmium pigments: in Situ identification and mapping in paintings. App/ Spectrosc 2011, 65:939-951.

39. Ricciardi P, Delaney JK, Facini M, Zeibel JG, Picollo M, Lomax S, Loew M: Near infrared reflectance imaging spectroscopy to map paint binders in Situ on illuminated manuscripts. Angewandte Chemie Int Ed 2012, 51:5607-5610

40. Dooley KA, Lomax S, Zeibel JG, Miliani C, Ricciardi P, Hoenigswald A, Loew M, Delaney JK: Mapping of egg yolk and animal skin glue paint binders in Early Renaissance paintings using near infrared reflectance imaging spectroscopy. Analyst 2013, 138:4838-4848.

41. Muir K, Langley A, Bezur A, Casadio F, Delaney J, Gautier G: Scientifically investigating Picasso's suspected use of Ripolin house paints in still life, 1922 and the red armchair, 1931. J Am Inst Conserv 2012, 52:156-172.

42. Rosi F, Miliani C, Braun R, Harig R, Sali D, Brunetti BG, Sgamellotti A: Noninvasive analysis of paintings by mid-infrared Hyperspectral imaging. Angewandte Chemie Int Ed 2013, 52:5258-5261.

43. Daffara C, Ambrosini D, Pezzati L, Mariotti PI: Mid-Infrared Reflectography for the Analysis of Pictorial Surface Layers in Artworks. In Proceedings 3rd International Topical Meeting on Optical Sensing and Artificial Vision. Edited by Gurov I. 2013:68-75

44. Legrand S, Alfeld M, Vanmeert F, De Nolf W, Janssens K: Macroscopic reflection Fourier Transformed Mid-Infrared (MA-rFTIR) scanning, a new technique for in situ imaging of painted cultural heritage artifacts. Analyst 2014, 139:2489-2498.

45. Legrand S: Ontwikkeling van een macroscopische Mid-Infrarood scanner. Antwerp, Belgium: University of Antwerp; 2012.

46. Monico L, Janssens $K$, Miliani C, Brunetti BG, Vagnini M, Vanmeert F, Falkenberg G, Abakumov A, Yinggang L, Tian H, Verbeeck J, Radepont M Cotte M, Hendriks E, Geldof M, Van der Loeff L, Salvant J, Menu M: The Degradation Process of Lead Chromate in paintings by Vincent van Gogh studied by means of Spectromicroscopic methods. 3: Synthesis, characterization and detection of different crystal forms of the chrome yellow pigment. Anal Chem 2012, 85:851-859.

47. Liang H, Cid MG, Cucu RG, Dobre GM, Podoleanu AG, Pedro J, Saunders D: En-face optical coherence tomography - a novel application of noninvasive imaging to art conservation. Opt Express 2005, 13:6133-6144.

48. Liang H, Peric B, Hughes M, Podoleanu A, Spring M, Saunders D: Optical Coherence Tomography for Art Conservation and Archaeology. In O3a: Optics for Arts, Architecture, and Archaeology, Proceedings of the SPIE 6618. 2007:05-12.

49. Targowski P, Iwanicka M, Tyminska-Widmer L, Sylwestrzak M, Kwiatkowska EA: Structural examination of easel paintings with optical coherence tomography. Acc Chem Res 2010, 43:826-836. 
50. Targowski P, Iwanicka M, Sylwestrzak M, Kaszewska EA, Frosinini C: OCT Structural Examination of 'Madonna dei Fusi' by Leonardo da Vinci. In Optics for Arts, Architecture, and Archaeology IV, Proceedings of the SPIE 8790. Edited by Pezzati L, Targowski P. 2013.

51. Targowski P, Iwanicka M: Optical Coherence Tomography: its role in the non-invasive structural examination and conservation of cultural heritage objects-a review. Appl Phys A Mater Sci Process 2012, 106:265-277.

doi:10.1186/2050-7445-2-13

Cite this article as: Legrand et al.: Examination of historical paintings by state-of-the-art hyperspectral imaging methods: from scanning infra-red spectroscopy to computed X-ray laminography. Heritage Science

2014 2:13.

\section{Publish with ChemistryCentral and every scientist can read your work free of charge \\ "Open access provides opportunities to our colleagues in other parts of the globe, by allowing anyone to view the content free of charge." \\ W. Jeffery Hurst, The Hershey Company. \\ - available free of charge to the entire scientific community \\ - peer reviewed and published immediately upon acceptance \\ - cited in PubMed and archived on PubMed Central \\ - yours - you keep the copyright \\ Submit your manuscript here: \\ http://www.chemistrycentral.com/manuscript/<smiles>c1ccccc1</smiles> 